\title{
Risk Factors and Likelihood of Campylobacter Colonization in Broiler Flocks
}

\begin{tabular}{l} 
Q Author(s) \\
\hline Kuana $S^{1}$ \\
Santos $L R^{1}$ \\
Rodrigues $L B^{1,2}$ \\
Borsoi $A^{3}$ \\
Moraes $H L S^{3}$ \\
Salle $C T P^{3}$ \\
Nascimento VP3 \\
1 Programa de Pós Graduação em Ciências \\
Veterinárias. PPGCV-UFRGS. \\
2 Faculdade de Agronomia e Medicina \\
Veterinária. FAMV - Universidade Passo \\
Fundo - UPF. \\
3 Faculdade de Veterinária - UFRGS. Centro \\
de Diagnóstico e Pesquisa em Patologia \\
Aviária. CDPA - UFRGS.
\end{tabular}

Mail Address

Vladimir Pinheiro do Nascimento UFRGS - Faculdade de Veterinária Av. Bento Gonçalves, 9090

91.540-000. Porto Alegre, RS, Brasil

E-mail: vladimir@orion.ufrgs.br

\section{Keywords}

Broilers, Campylobacter, cecal droppings, cloacal swabs, feces.

\section{ABSTRACT}

Campylobacterwas investigated in cecal droppings, feces, and cloacal swabs of 22 flocks of 3 to 5 week-old broilers. Risk factors and the likelihood of the presence of this agent in these flocks were determined. Management practices, such as cleaning and disinfection, feeding, drinkers, and litter treatments, were assessed. Results were evaluated using Odds Ratio (OR) test, and their significance was tested by Fisher's test $(p<0.05)$. A Campylobacter prevalence of $81.8 \%$ was found in the broiler flocks (18/22), and within positive flocks, it varied between 85 and $100 \%$. Campylobacter incidence among sample types was homogenous, being $81.8 \%$ in cecal droppings, $80.9 \%$ in feces, and $80.4 \%$ in cloacal swabs (230). Flocks fed by automatic feeding systems presented higher incidence of Campylobacter as compared to those fed by tube feeders. Litter was reused in $63.6 \%$ of the farm, and, despite the lack of statistical significance, there was higher likelihood of Campylobacter incidence when litter was reused. Foot bath was not used in $45.5 \%$ of the flocks, whereas the use of foot bath associated to deficient lime management increased the number of positive flocks, although with no statiscal significance. The evaluated parameters were not significantly associated with Campylobacter colonization in the assessed broiler flocks.

\section{INTRODUCTION}

Poultry are important Campylobacter reservoirs, with 50 to $70 \%$ of human infections related with food preparation flaws and the consumption of poultry products (FAOMHO, 2001). Campylobacter is frequently detected in the digestive tract of poultry, and particularly of broilers older than three weeks of age, rapidly disseminating until market age (Stern \& Robach, 1995; Jacobs-Reitsma, 1995).

Campylobacterincidence in broilers may be related to to management practices, such as feed distribution, litter and water treatment, workers' protection, poultry house downtime, and the presence of other domestic animals (Hald et al., 2000; Berndson et al., 1996). Interventions on these factors could reduce the contamination by this agent (Pattison, 2001).

Therefore, Campylobacter was researched in the cecal droppings, feces, and cloacal swabs of 22 flocks of 3 to 5 week-old broilers in order to determine risk factors and likelihood of the presence of this agent in these flocks.

\section{MATERIAL AND METHODS}

The study was carried out from October to November, 2002, in broiler farms belonging to a company in the state of Santa Catarina, Brazil. A questionnaire was applied to investigate, using case-control study of 


\section{Cromberg VU, Stein MS, Boleli IC, Tonhati H, Queiroz SA}

Risk Factors and Likelihood of Campylobacter Colonization in Broiler Flocks risk factors (relative to farm biosecurity), the likelihood of contamination of a broiler flock by Campylobacter. The studied region presents high density of poultry farms. The evaluated poultry houses had dirt floor. Wood-shavings litter was reused for at least eight production cycles, and turned daily or every two days. The experimental unit was the poultry house (one house = one farm), which represented the flock, as it presented the same inherent and intrinsic conditions of the entire farm. Twenty two broilers houses (three measuring $600 \mathrm{~m}^{2}$ and 19 measuring $1.200 \mathrm{~m}^{2}$ ) were monitored. Farms with flock ages older than three weeks of age were randomly selected. This age was chosen because there is a higher and increasing Campylobacter colonization up to market age (Stern, 1995).

\section{Chicks derived from different origins.}

Broiler houses were equipped with nipple drinkers, automatic or tube feeders, and feed and water were offered ad libitum. Average bird density was 15 birds/ $\mathrm{m}^{2}$.

Sampling plan consisted of a prospective transversal cut for a period of two months, during which 22 broiler houses were monitored. The number of birds monitored per flock varied between 9.027 and 70.179 flocks, representing a total number of 576.617 birds housed in an all-in, all-out production system. The presence of Campylobacter was assessed in 450 samples at the company's laboratory.

\section{Campylobacter research}

Samples were randomly collected from 20 birds per flock, being 10 cloacal swabs, five feces samples, and five cecal droppings samples. Minimum bird age was 27 days, and maximum, 33 days.

The collected cloacal swabs were immediately place in Cary Blair Medium (CM 519, Oxoid $^{\circledR}$ ) transport medium, in a total number of 230 samples. Both fresh feces and cecal droppings samples were collected in individual sterile plastic 50-ml flasks, in a total of 110 samples each. All samples were placed refrigerated, submitted to the laboratory in an ice-box, and processed immediately after arrival.

Campylobacter was researched using mCCDA culture medium (CM739, Oxoid $\left.^{\circledR}\right)$ with selective supplement (SR155, Oxoid). Counting was performed in Bolton broth (CM983, Oxoid) supplemented with antibiotics (SR183E, Oxoid), $15 \mathrm{~g} / \mathrm{L}$ agar, 0.5g/L iron sulfate, and $200 \mathrm{mg} / \mathrm{L}$ TTC. Samples were incubated in microaerophilic environment with $5 \% \mathrm{O}_{2}, 10 \% \mathrm{CO}_{2}$, and $85 \% \mathrm{~N}_{2}$ for $48 \mathrm{~h}$, and the suspected colonies were presumptively identified by catalase and oxydase, and confirmed in latex.

\section{Risk factors and likelihood of the occurrence of Campylobacter}

The people responsible for hygiene and biosecurity management of the 22 studied flocks were asked to answer a questionnaire. Cloacal swabs, and feces and cecal droppings samples were collected from these flocks for bacterial analyses. A flock was considered positive for Campylobacter if a single analyzed sample was positive for this agent.

The following parameters were evaluated: cleaning and disinfection procedures, disinfectant type and use, feeding practices (feed and water systems), woodshavings litter management, chlorinated water use, presence and effective use of foot bath, hand hygiene, use of flock-dedicated footware, presence of domestic animals, flock health as to medication use when disease occurred.

The relation of events and non-events between the studied group and the control group for each evaluated parameter assessed using Odds Ratio (OR) test, with the significance tested using Fisher's test $(P<0.05)$, by the Statistical Package for the Social Sciences (SPSS). When the parameter presented an $O R>1.0$, it was considered a risk factor.

\section{RESULTS AND DISCUSSION}

Out of the studied broiler flocks, $81.8 \%$ were positive for Campylobacter, but the evaluated parameters were not significantly associated with colonization by this agent (Table 1).

Automatic feeding systems were used in $59 \%$ of the flocks, and presented a higher number and higher likelihood $(\mathrm{OR}=0.64)$ of positive flocks as compared to flocks using tube feeders.

In $63.6 \%$ of the farms, litter was reused more than once, with a higher likelihood $(\mathrm{OR}=2.0)$ of being infected with Campylobacter, but this was not statistically significant. Litter treatment by piling is common during downtime, and this was used in $68.2 \%$ of the flocks, which presented lower likelihood $(\mathrm{OR}=0.67)$ of infection. However, a higher likelihood of Campylobacter infection was observed when the litter was treated with lime.

Water well was used in $45.5 \%$ of the flocks, and presented higher likelihood of Campylobacter colonization $(\mathrm{OR}=3.00)$, but this was not statistically significant. Water was not treated with chlorine in 63.6 


\begin{tabular}{|c|c|c|c|c|}
\hline & N. positive flocks & N. negative flocks & Odds ratio(OR) & $p$ \\
\hline \multicolumn{5}{|l|}{ Feeder type } \\
\hline Tube & 7 & 2 & 0.64 & 1.00 \\
\hline Automatic & 11 & 2 & & \\
\hline \multicolumn{5}{|l|}{ Litter } \\
\hline Reused $>1$ time & 12 & 2 & 2.00 & 1.00 \\
\hline Reused $=1$ time & 6 & 2 & & \\
\hline Piling & 12 & 3 & 0.67 & 1.00 \\
\hline Lime treatment & 6 & 1 & & \\
\hline \multicolumn{5}{|l|}{ Water } \\
\hline Well & 9 & 1 & 3.00 & 0.59 \\
\hline Spring & 9 & 3 & & \\
\hline \multicolumn{5}{|l|}{ Chlorinated water } \\
\hline No & 11 & 3 & 0.52 & 1.00 \\
\hline Yes & 7 & 1 & & \\
\hline \multicolumn{5}{|l|}{ Dedicated footware } \\
\hline No & 3 & 1 & 0.60 & 1.00 \\
\hline Yes & 15 & 3 & & \\
\hline \multicolumn{5}{|l|}{ Foot bath } \\
\hline No & 7 & 3 & 0.21 & 0.29 \\
\hline Yes & 11 & 1 & & \\
\hline Good management & 7 & 0 & * & 0.42 \\
\hline Poor management & 4 & 1 & & \\
\hline \multicolumn{5}{|l|}{ Downtime } \\
\hline$<=10$ days & 5 & 1 & 0.50 & 1.00 \\
\hline$>10$ days & 10 & 1 & & \\
\hline \multicolumn{5}{|l|}{ Presence of dogs } \\
\hline Yes & 16 & 4 & * & 1.00 \\
\hline No & 2 & 0 & & \\
\hline \multicolumn{5}{|l|}{ Presence of cats } \\
\hline Yes & 9 & 4 & * & 0.12 \\
\hline No & 9 & 0 & & \\
\hline \multicolumn{5}{|l|}{ Presence of goats } \\
\hline Yes & 4 & 0 & * & 0.55 \\
\hline No & 14 & 4 & & \\
\hline \multicolumn{5}{|l|}{ Presence of swine } \\
\hline Yes & 12 & 3 & 0.67 & 1.00 \\
\hline No & 6 & 1 & & \\
\hline
\end{tabular}

$P$ - by Fisher's Exact Test. $\mathrm{OR}>1.00$ is considered as a risk factor. ${ }^{*}$ Cell equal to zero: it was not possible to calculate OR.

$\%$ of the flocks, and presented low likelihood $(\mathrm{OR}=0.52)$ of flock contamination. However, chlorinated drinking water was did not prevent Campylobacter colonization of positive flocks, as suggested by Pattison (2001) and Stern et al. (2002).

Stockpeople did not use dedicated footware to enter the broiler houses in $18.2 \%$ of the flocks, but this parameter presented low likelihood of Campylobacter contamination $(\mathrm{OR}=0.60)$. In fact, the number of positive flocks was higher when the stockpeople said they changed their footware. However, as they did this inside their own houses, shoe contamination possibly occurred on the way to the broiler houses, as there were dogs and other domestic animals in adjacent areas.

Foot baths were absent in $45.5 \%$ of the flocks, presenting a lower number of events $(O R=0.21)$. However, when present but associated to poor lime management, it presented a higher number of positive flocks, depite the lack of statistical significance. Evans \& Sayers (2000) recommend the effective use of foot bath and changing footware to delay the colonization by Campylobacter in broiler flocks.

Hald et al. (2000) demonstrated that downtime shorter than 14 days was a potential and significant risk factor for the colonization by Campylobacter. In contrast, in the present study, downtime shorter or equal to ten days presented lower likelihood of Campylobacter events $(\mathrm{OR}=0.50)$, whereas downtime longer than ten days resulted in a higher number positive flocks.

Other domestic animals were present in all farms; however, it was not possible to calculate the OR for some species, due the absence of frequency of some factors. In general, dogs, cats, and goats were present. Despite being a parallel activity in the region, the presence of swine in an adjacent, but separate area of the farm, was not a risk factor $(\mathrm{OR}=0.67)$. 


\section{Cromberg VU, Stein MS, Boleli IC, Tonhati H, Queiroz SA}

The microbiological analysis identified that $81.8 \%$ of the studied flocks were positive for Campylobacter. Even in farms with good management practices, there was Campylobacter colonization of broilers, which suggests that hygiene could be improved, and that it is essential to decrease colonization up to market age (Stern et al., 2001).

Alternatives for the reduction of Campylobacter colonization, such as the use of probiotics, carbohydrates, and fructoligosaccharides in the feed or drinking water, are new areas to be studied for possible application in commercial broiler production. On the other hand, strategic interventions need to be developed for breeder farms, hatchers and hatchery environment to check the potential of vertical transmission of Campylobacter to the progeny (Cox et al., 2002).

\section{CONCLUSION}

The parameters evaluated as risk factors were not significantly associated with Campylobacter colonization in the studied broiler flocks, which were $81.8 \%$ positive, as determined by bacteriological analyses.

\section{REFERENCES}

Berndtson E, Danielsson-Tham ML, Engvall A. Campylobacter incidence on a chicken farm and the spread of Campylobacter during slaughter process. International Journal of Food Microbiology 1996; 32:35-47.
Risk Factors and Likelihood of Campylobacter Colonization in Broiler Flocks

Cox NA, Stern NJ, Hiett KL. Identification of a new source of Campylobactercontamination in poultry: transmission from breeder hens to broiler chickens. Avian Diseases 2002; 46:535-541.

Evans SJ, Sayers AR. A longitudinal study of Campylobacterinfection of broiler flocks in Great Britain. Preventive Veterinary Medicine 2000; 46:209-223.

Food and Agriculture Organization of the Unit Nations. World Health Organization. Hazard identification, hazard characterization and exposure assessment of Campylobacterspp. in broiler chicken: activities on risk assessment of microbiological hazard in foods, preliminary report, 2001. [cited 2001 may 30]. Available from: www.fao.org/es/ESN/pagerisk/campy.pdf.

Hald B, Wedderkopp A, Madsen M. Thermophilic Campylobacter spp. in Danish broiler production: a cross-sectional survey and a retrospective analysis of risk factors for occurrence in broiler flocks. Avian Pathology 2000; 29:123-131.

Jacob-Reitsma WF. Campylobacter bacteria in breeder flocks. Avian Diseases 1995; 39:355-359.

Pattison M. Practical intervention strategies for Campylobacter. Journal of Applied Microbiology 2001; 90:121-125.

Stern NJ, Robach MC. Non-destructive sampling of live broilers for Campylobacter. Journal Applied Poultry Research 1995; 4: 182185.

Stern NJ, Fedorka-Cray P, Bailey JS. Distribution of Campylobacter spp. in selected U.S poultry production and processing operations. Journal of Food Protection 2001; 64 (11):1705-1710.

Stern NJ, Robach MC, Cox NA, Musgrove MT. Effect of drinking water chlorination on Campylobacter spp. colonization of broilers. Avian Diseases 2002; 46: 401-404. 